\title{
CORRESPONDENCE
}

SiR,

\section{To THE EDITOR of Philosophy}

I do not think that discussions about reviews of books are often very edifying, but Professor H. A. Wolfson's remarks in the April number about my review of his The Philosophy of Spinoza appear to call for brief reply.

It is, perhaps, characteristic of the scholastic mode of approach favoured by Mr. Wolfson to rest content with lists of rival authorities rather than to attack problems directly. He may take it as additional evidence of my "supreme faith in (my) own convictions" if I say that I might have reached my conclusion about geometrical proofs being non-syllogistic even if Mr. Joseph had not written his invaluable book from which Mr. Wolfson seems to suppose I must have derived it. Mother-wit and simple examination of the facts will often carry one much further than reliance upon authority. After all, someone must discover truths, and thus do without an authority; and some truths are so obvious as to be constantly rediscovered by new inquirers. "Aristotle was certainly a knowing man, but nobody ever thought him so because he blindly embraced and confidently vented the opinions of another."

If I might, without offence, be brief and brutal, I should argue thus: Geometrical proofs are conclusive, and their conclusions are A-propositions predicting specific propria. Now A-propositions can only be conclusively established syllogistically by the mood Barbara. But Barbara proves only generic propria (as the dictum de omni emphasizes). Hence geometrical propositions are not established by means of syllogisms.

Yours, etc.,

H. F. Hallett.

University OF LONDON KING'S COLLEGE, Strand, W.C.2.

April 2, 1936. 